\title{
Laser therapy in 100 tracheobronchial tumours
}

\author{
MR HETZEL, C NIXON, WM EDMONDSTONE, DM MITCHELL, FJC MILLARD, \\ EM NANSON, AA WOODCOCK, CE BRIDGES, AM HUMBERSTONE
}

From University College Hospital and St James's Hospital, London

\begin{abstract}
One hundred patients with tracheobronchial tumours were treated with the neodymium YAG (yttrium-aluminium-garnet) or argon laser for symptoms of airways obstruction caused by tumour ( 59 cases), complete collapse of a lung (17 cases), or recurrent haemoptysis ( 24 cases). Seventy four of them had relapsed or failed to respond to radiotherapy or chemotherapy and all were inoperable. Objective improvement in results of lung function tests or haemoptysis diary charts was seen in 37 patients with airways obstruction (63\%), five (29\%) with collapsed lung, and 14 (58\%) with haemoptysis. Overall, 68 patients had symptomatic benefit and there was objective improvement in 56. Two deaths occurred in 288 treatment sessions both occurring as a result of asphyxia from minor haemorrhage in patients with advanced cylindromas and critical narrowing of the trachea or single remaining bronchus. In suitable patients with intraluminal tumour laser phototherapy is a valuable addition to conventional treatment.
\end{abstract}

We have previously reported our early experience with the neodymium yttrium-aluminium-garnet (Nd-YAG) and argon lasers in the palliative treatment of advanced tracheobronchial tumours.' Other authors have described similar series ${ }^{2}{ }^{4}$ This paper describes results for our first 100 cases, with particular reference to improvements in technique and the relative merits of treatment under local and general anaesthesia.

\section{Patients and methods}

Patients were recruited who had histologically proved and inoperable tracheal or bronchial tumours which were causing symptoms of breathlessness or recurrent haemoptysis. Previous attempts at palliation with radiotherapy or chemotherapy either had failed or symptoms had recurred after an earlier response. In some cases laser was the first attempt at treatment because patients were considered unfit for conventional treatment or had refused it. They were given laser treatment if at bronchoscopy our initial impression was that symptoms were mainly attributable to intraluminal tumour which was accessible to the bronchoscope; in most cases, however, there was also extrinsic compression of the airway, presumably

Address for reprint requests: Dr FJC Millard, St James's Hospital, London SW12 8HW.

Accepted 21 December 1984 due to tumour outside the bronchial wall. Although many patients had metastases, symptoms were mainly attributable to local disease at the primary site.

If clearance of the airways was considered inadequate at the first attempt, we were prepared to give up to three sessions of laser treatment during the initial admission to hospital, after which no further treatment was attempted if the patient did not improve. Follow up treatments were given at one to three month intervals, depending on the speed with which symptoms recurred, for as long as further response was seen and breathlessness or haemoptysis remained predominant symptoms.

Response to treatment was assessed by the patients' account of their symptoms and by the results of pulmonary function tests, which included peak expiratory flow rate, spirometric values, and a flow-volume loop. Exercise tolerance was measured by the six minute walking test. ${ }^{5}$ Full pulmonary function testing was not completed in a few of our early patients and could not be performed in some patients because of extreme breathlessness, but peak flow rate was always attempted on the ward with a Wright peak flow meter. These tests were performed before and after treatment and repeated at outpatient sessions and before subsequent treatments. A symptomatic improvement was recorded if the patient said that he or she felt better and if there was an improvement in the six minute walk. Objective improvement was recorded if there was a grea- 
ter than $25 \%$ rise in peak flow rate, since this information was consistently available. Such cases usually showed improvement in spirometric indices and flow-volume loops as well. In patients with an unrecordable peak flow $601 \mathrm{~min}-{ }^{-1}$ was taken as the starting point for this calculation.

In patients treated for haemoptysis diary charts were recorded from the time of admission for assessment for laser treatment. After discharge home records were continued by the patient, who was asked to record each day whether blood had been coughed up and if so how much. An objective response was defined as complete cessation of haemoptysis for at least one month. A symptomatic response was defined as a significant reduction in frequency and quantity of haemoptysis. It was considered unjustifiable to delay treatment for more than a few days to monitor haemoptyses before the first treatment. In patients who were subsequently treated again (for recurrence of haemoptyses after initial good control) it was, however, possible to compare pre-treatment and post-treatment records covering several weeks. Diary charts were also used to help in deciding when further treatment was indicated.

The first 14 patients were treated with the argon laser (Spectra Physics), wavelength 488 and $514 \mathrm{~nm}$, output $12 \mathrm{w}$. All other patients were treated with the neodymium YAG laser (Barr and Stroud or Medilas), wavelength $1060 \mathrm{~nm}$, maximum output $100 \mathrm{w}$. The laser beam was transmitted through a $200 \mu \mathrm{m}$ quartz (argon) or 600 micron glass (Nd YAG) optical fibre. The fibre has no lens on its distal end, so the laser beam diverges at the fibre tip and has an effective operating distance of 0.5-1.0 $\mathrm{cm}$. To aim the laser the fibre is passed through the suction channel of an Olympus BF1TR fibreoptic bronchoscope (2.6 $\mathrm{mm}$ suction channel) and positioned with the aid of an aiming beam. For the argon laser the attenuated argon beam is used as an aiming beam; for the Nd YAG, where the beam itself being in the near infrared region, is invisible, a coupled helium neon laser provides a red aiming beam. Any debris collecting on the fibre tip will absorb the energy of the laser light with generation of temperatures high enough to chip the fibre tip and distort the laser beam. To reduce this effect the fibre is enclosed in a teflon tube, through which compressed air is blown to keep the tip clean. Suitable filters in the bronchoscope eyepiece protect the bronchoscopist's eyes.

For 84 patients (all 14 treated with argon laser and 70 treated with the Nd YAG) the fibrescope was used under local anaesthesia with $4 \%$ lignocaine to the nasopharynx and larynx and $2 \%$ to the bronchial tree. Premedication was with atropine and papaveretum; additional sedation was achieved with intravenous diazepam. When necessary, small doses of intravenous diamorphine were used in addition to the diazepam to suppress coughing. Five of these patients had subsequent treatment under general anaesthetic.

In 21 cases general anaesthesia was induced with etomidate at a rate of $0.1 \mathrm{mg} / \mathrm{kg} /$ minute for 10 minutes and then maintained by intravenous infusion at a rate of $0.02-0.04 \mathrm{mg} / \mathrm{kg} / \mathrm{min}$. After induction patients were paralysed with atracurium 0.5 $\mathrm{mg} / \mathrm{kg}$ and a Storz $7.5 \mathrm{~mm}$ adult ventilation rigid bronchoscope was passed into the trachea. Jet ventilation was then used with a Sanders injector, with 78-100\% oxygen entraining room air. Paralysis was maintained with boluses of atracurium of $0.2 \mathrm{mg} / \mathrm{kg}$ at 20 minute intervals. Enhancement of analgesia and anaesthesia was achieved with small doses of alfentanil. The fibrescope, passed through the rigid bronchoscope, was used to aim the laser beam. Debris was removed with rigid biopsy forceps. At the end of treatment the rigid bronchoscope was removed, an endotracheal tube passed, and mechanical ventilation used with nitrous oxide and oxygen, until spontaneous breathing occurred after reversal of neuromuscular blockade with atropine and neostigmine.

The lasers were used in pulses of one to two seconds' duration at outputs of $12 \mathrm{w}$ for the argon laser and $70 \mathrm{w}$ for the $\mathrm{Nd}$ YAG.

\section{Results}

There were 60 men and 40 women (mean age 65 , range $27-83$ years). The cell type was squamous cell in 78 patients, adenocarcinoma in 10, large cell undifferentiated in four, small cell in one, carcinoid in one, and cylindroma in two. Four patients had metastatic or invading tumour from primary tumours outside the tracheobronchial tree (thyroid papillary carcinoma, thyroid follicular carcinoma, cervical mesonephric tumour and adenocarcinoma of the colon). Sixty four patients had had previous treatment with radiotherapy, 12 had been treated surgically and 11 had received chemotherapy. Twenty six patients had laser therapy alone.

The indication for laster phototherapy was partial obstruction of the trachea, carina, or a major bronchus in 59 patients; complete obstruction with collapse of a lung or lobe in 17; and recurrent haemoptysis in 24. Results for these three categories are summarised in table 1 , which shows that some symptomatic benefit was seen in 68 patients overall and that objective benefit could be measured in 56 .

PARTIAL OBSTRUCTION

Of 59 cases treated, $45(76 \%)$ had a symptomatic 
Table 1 Indications for laser treatment and response

\begin{tabular}{|c|c|c|c|}
\hline \multirow[t]{2}{*}{ Indication } & \multirow[t]{2}{*}{$n$} & \multicolumn{2}{|c|}{ No (\%) showing } \\
\hline & & $\begin{array}{l}\text { Symptomatic } \\
\text { response }\end{array}$ & $\begin{array}{l}\text { Objective } \\
\text { response }\end{array}$ \\
\hline $\begin{array}{l}\text { Partial obstruction } \\
\text { Complete collapse of lung or lobe } \\
\text { Haemoptysis } \\
\text { Total treated }\end{array}$ & $\begin{array}{r}59 \\
17 \\
24 \\
100\end{array}$ & $\begin{array}{r}45(76) \\
7(38) \\
16(67) \\
68(68)\end{array}$ & $\begin{array}{r}37(63) \\
5(29) \\
14(58) \\
56(56)\end{array}$ \\
\hline
\end{tabular}

Table 2 Effect of tumour site on response to laser treatment

\begin{tabular}{|c|c|c|c|}
\hline \multirow[t]{2}{*}{ Site of tumour } & \multirow[t]{2}{*}{$n$} & \multicolumn{2}{|c|}{ No (\%) showing } \\
\hline & & $\begin{array}{l}\text { Symptomatic } \\
\text { response }\end{array}$ & $\begin{array}{l}\text { Objective } \\
\text { response }\end{array}$ \\
\hline $\begin{array}{l}\text { Trachea } \\
\text { Carina } \\
\text { Main bronchus } \\
\text { Lobar bronchus and mixed sites } \\
\text { Total }\end{array}$ & $\begin{array}{r}13 \\
17 \\
22 \\
7 \\
59\end{array}$ & $\begin{array}{r}12(92) \\
13(76) \\
17(77) \\
3(43) \\
45(76)\end{array}$ & $\begin{array}{l}10(77) \\
11(65) \\
13(59) \\
3(43) \\
37(63)\end{array}$ \\
\hline
\end{tabular}

response and in $37(63 \%)$ there was an objective improvement of more than $25 \%$ in peak flow rate. In these 37 cases mean peak expiratory flow rate (PEFR) was $1491 \mathrm{~min}^{-1}$ before treatment and after treatment $2501 \mathrm{~min}^{-1}$. Mean percentage improvement in PEFR was $88 \%$, range $25 \%(120-1501$ $\left.\min -^{-1}\right)$ to $533 \%\left(60-3801 \mathrm{~min}^{-1}\right)$. Some relationship was seen between site of tumour and response to treatment (table 2), with benefit most frequently seen in tumours of the trachea and carina.

\section{COMPLETE OBSTRUCTION AND COLLAPSE}

Of 17 cases of complete obstruction of a bronchus with collapse of a lung or lobe, re-expansion was achieved in five. In two cases re-expansion was complicated by pneumonia in the treated lung, and this undoubtedly hastened death in these patients. Subsequently prophylactic treatment with ampicillin and metronidazole in other cases treated for complete obstruction appeared to reduce the risk of pneumonia. Several treatments were needed to achieve re-expansion when local anaesthesia was used, but two patients treated under general anaesthesia achieved re-expansion in a single treatment.

\section{HAEMOPTYSIS}

Of 24 cases treated for haemoptysis, complete remission was achieved for at least one month in 14 (58\%). Repeat treatments were successful on relapse in these cases. In a further two cases some improvement was seen but death occurred within one month. Thus some improvement was seen in a total of 16 patients $(67 \%)$. Failure to respond was usually attributable to inadequate detection of the precise site of haemorrhage at bronchoscopy.

\section{TREATMENT FREQUENCY AND OPERATIVE} MORTALITY

Fourteen patients treated with argon laser and local anaesthesia had a total of 64 treatments. Seventy patients treated with the Nd YAG laser under local anaesthesia had 194 treatment sessions. Twenty one patients treated with Nd YAG laser under general anaesthesia had 30 treatment sessions (five of these patients had also previously had treatment with the Nd YAG laser under local anaesthesia). Duration of treatment sessions varied considerably with the extent and accessibility of the tumour and (under local anaesthesia) the patient's tolerance of the procedure. Treatment under local anaesthesia could not be tolerated beyond a maximum of one hour; thus several treatments were often required for adequate clearance of the airway. Adequate clearance of accessible tumour under general anaesthesia could usually be achieved in a single treatment of one hour and never exceeded two hours.

In the total of 288 treatments there were two operative deaths (operative mortality $0.69 \%$, overall mortality $2 \%$ of patients treated). Both deaths occurred in patients with cylindromas treated under local anaesthesia and resulted from asphyxia due to relatively mild haemorrhage in an already severely compromised airway. One of these patients, a 61 year old man with tumour in the lower trachea and carina, had previously had good control of symptoms and objective improvement from laser treatment over the previous three months (peak flow rate then 220-3201 min-1, but unrecordable at his final admission). The other, a 48 year old woman, had previously had a pneumonectomy and a recurrence of tumour causing near total obstruction of the 


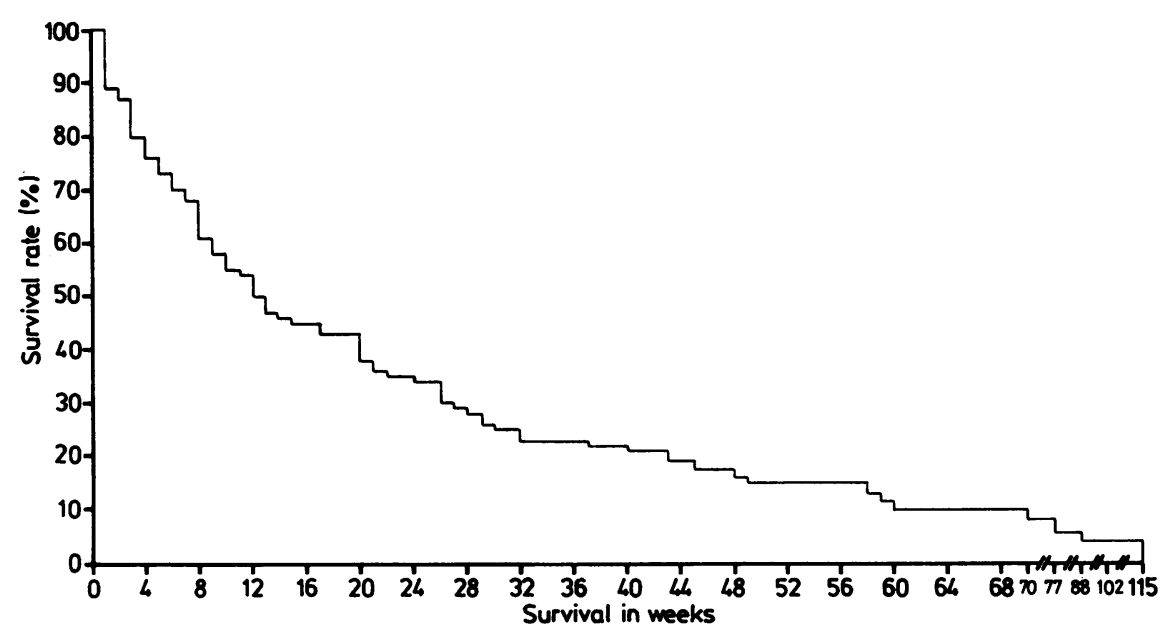

Cumulative survival curve (at weekly intervals from date of first treatment by laser) for the 100 patients studied. Sixty eight responded and 32 did not.

orifice of the remaining right bronchus. We were unable to record her peak flow rate at the time of her referral to us. In the opinion of the anaesthetist $(\mathrm{CN})$ the risk of general anaesthesia was unacceptably high. The risks of laser treatment were obviously considerable in these two patients but were considered justified by the lack of alternative treatment, the patients' distress from their severe stridor, and their determination to be treated rather than suffer their symptoms further. The only other sequela of treatment was the occasional need to remove viscid exudate after treatment by follow up bronchoscopy. This has not yet been necessary after rigid bronchoscopy, probably because more effective clearance of the airway was possible at a single treatment. One patient treated with rigid bronchoscopy and jet ventilation developed a pneumothorax which required intercostal drainage. Otherwise treatment was well tolerated, with full recovery usually evident within 24 hours.

\section{SURVIVAL}

The figure shows the cumulative survival curve for the 100 patients recruited. Sixty eight showed at least symptomatic benefit from laser phototherapy and were given further treatments on relapse, and there were 32 non-responders, who had no evidence of palliative benefit and who were not treated again. No control group of similar patients not treated with the laser is available for analysis of the effect of laser phototherapy on survival.

\section{Discussion}

This larger series, with improvements in our techni- cal expertise, confirms our earlier view ${ }^{1}$ that, in patients with predominantly intraluminal tumours, laser phototherapy is a valuable palliative treatment that may be effective when radiotherapy or chemotherapy have failed. It has advantages of immediate response, no systemic toxícity, and no dosage limit. It is most effective when used for clearing partial obstruction due to tumours in the trachea or at the carina. For haemoptysis results were encouraging, provided that the site of bleeding could be identified. In our hands an overall mortality of $2 \%$ was acceptable in these patients with advanced tumours and poor respiratory function. Reexpansion of collapsed lungs is technically more difficult. There are no anatomical landmarks to ensure the correct line of cut through the completely obstructing tumour. It is also impossible to assess the extent of tumour or viability of the lung once collapse has occurred. Risk of pneumonia is probably increased if only a small airway can be established. Attempts should be made to clear the bronchus thoroughly and vigorous physiotherapy and prophylactic antibiotic treatment are obvious precautions.

Our assessment of these cases was limited to simple spirometry and exercise tests. Laser phototherapy may have improved ventilation only to the re-expanded lung; we have no information about its effects on perfusion. More complex tests-for example, ventilation-perfusion lung scanningmight have been useful in these cases and further studies are in progress.

The Nd YAG laser penetrates more deeply than the argon laser, achieving greater tumour destruction, and we now use it exclusively. The fibreoptic 
bronchoscope under local anaesthesia is favoured by some workers ${ }^{4}$ but has the disadvantage of small forceps, so that patients may need several treatment sessions. Rigid bronchoscopy under general anaesthesia ${ }^{23}$ uses larger forceps to clear debris and fewer sessions are therefore required. Prolonged intravenous anaesthesia does, however, pose problems, particularly in speed of recovery from anaesthesia, and further refinement of the anaesthetic technique is desirable. With our limited experience we cannot yet compare the operative mortalities associated with general and local anaesthesia. No study of laser phototherapy in bronchial tumours has yet provided data on the effect of treatment on survival. Our series also lacks a control group, but this is difficult to justify in patients who present in such a desperate condition, often after all other treatments have failed. In the light of the brief survival after attempts at palliative laser treatment in some of these patients, (figure), it might be questioned whether treatment was worthwhile. We have shown that it was reasonably safe and well tolerated and that some patients enjoyed relief of their distressing symptoms for many months (figure). Even those responders who survived only for a short time obtained a brief period of relief from their most troublesome svmptoms.

Laser photodynamic therapy with haematoporphyrin derivative (HpD) also has exciting potential. $\mathrm{HpD}$ is retained selectively by tumour cells and 72 hours after an intravenous dose can be activated by a rhodamine B dye laser, causing the formation of singlet oxygen and tumour cell death. ${ }^{6}$ It can produce effective palliation ${ }^{7-10}$ but complications, such as the formation of tenacious sputum, fever, pneumonia, and abscess formation, are common..$^{10}$ There have been two deaths from postoperative haemorrhage $^{8}$ and skin photosensitivity persists for several weeks after treatment. It has therefore disadvantages for palliation compared with the $\mathrm{Nd}$ YAG laser although it is possible that future refinements may reduce the toxicity of laser treatment with HpD.

We conclude that laser phototherapy can make a significant contribution to the management of tracheobronchial tumours. Its full potential for this purpose has yet to be established. Animal studies ${ }^{11}$ have shown that the Nd YAG laser can, in sufficient dosage, destroy tumours and prevent recurrence. The safety record and simplicity of use of the $\mathrm{Nd}$ YAG laser now justify treatment of inoperable cases at an earlier stage, with a view to better palliation and survival than could have been hoped for in the near terminal cases that we have so far treated.

This study was partly supported by a small grant from the Office of the Chief Scientist, Department of Health and Social Security. We are grateful to our nursing staff, V Darkazally, A Ramu, and S Dina, and to Drs SG Brown, P Swain, and T Mills for their advice and technical help.

\section{References}

1 Hetzel MR, Millard FJC, Ayesh R, et al. Laser treatment for carcinoma of the bronchus. $\mathrm{Br}$ Med $J$ 1983;286: 12-6.

2 Toty L, Personne C, Colchen A, Vourc'h G. Bronchoscopic management of tracheal lesions using the neodymium-yttrium-aluminium garnet laser. Thorax 1983;36: $175-8$.

3 Dumon JF, Reboud E, Garbe L, Aucomte F, Meric B. Treatment of tracheo-bronchial lesions by laser photoresection. Chest 1982;81:278-84.

4 Hauberger K, Held E, Huber R. Endobronchial laser therapy-differential therapeutic use and clinical value. Klin Wochenschr 1984;62:74-80.

5 Butland RJA, Pang JA, Gross ER, Woodcock AA, Geddes DM. Two-, six- and twelve-minute walking tests in respiratory disease. $\mathrm{Br} \mathrm{Med} J$ 1982;284:16078.

6 Weishaupt KR, Gomer CJ, Dougherty TJ. Identification of singlet oxygen as the cytotoxic agent in photoinactivation of a murine tumour. Cancer Res 1976;36:2326-9.

7 Hayata Y, Kato H, Konaka C, Ono J, Takizawa N, Kato W. Haematoporphyrin derivative and laser photoradiation in the treatment of lung cancer. Chest 1982;81:269-77.

8 Cortese DA, Kinsey JH. Endoscopic management of lung cancer with haematoporphyrin derivative phototherapy. Proc Mayo Clinic 1982;57:543-7.

9 Forbes IJ, Cowled PA, Leong AS, et al. Phototherapy of human tumours using haematoporphyrin derivative. Med J Aust 1980;ii:489-93.

10 Vincent RG, Dougherty TJ, Rao U, Boyle DG, Potter WR. Photoradiation therapy in advanced carcinoma of the trachea and bronchus. Chest 1984;85:29-33.

11 Gardner W, Hugh-Jones P, Carroll MA, Hewitt ER, Hewitt HB, Whimster W. Quantitative analysis of effect of neodymium-YAG laser on transplanted mouse carcinoma. Thorax 1982;37:594-7. 